\title{
The tube of Ditrupa bartonensis (Annelida, Serpulidae), from the Eocene of southern England: Observations on microstructure and its significance
}

\author{
James O. Buckman
}

\begin{abstract}
Exceptionally well-preserved examples of the calcareous annelid tube Ditrupa bartonensis occur within clays of the Eocene Barton Beds Formation of Hampshire, UK, where it is the most common of four recorded annelid species $(D$. bartonensis, Protula extensa, Pyrgopolon (Serpula) crassa, Pyrgopolon (Sclerostyla) mellevillei). The current work confirms that i) chevron-shaped lamellae are present within Ditrupa, and that ii) all microstructures in Ditrupa are conservative (Eocene to present) - including the inner tube structure, which has only been previously recorded from extant material. New observations of the regularly ridged prismatic (RRP) structure of the outer layer illustrate the occurrence of conchoidal fractures, which are likely to represent the influence of acidic proteins within their calcite crystalline structure. The occurrence of conchoidal fractures, and the intricate non-crystalline external appearance of RRP structure, suggests a similar mode of formation to that of the single calcite crystals that form the plates and spines within echinoderms, and likely reflect an adaptation for tube strengthening, as previously postulated. A tentative model for RRP construction based on the formation of echinoderm single calcite crystals is suggested with the aim of stimulating further research. The inner layer, which comprises partially aligned slender prismatic crystals, was previously referred to as irregularly orientated prismatic (IOP) fabric, but does not fit the original description. Therefore, simple preferentially orientated prismatic (SPOP) is introduced for such fabric that forms the inner layer of Ditrupa.
\end{abstract}

James O. Buckman. Institute of GeoEnergy Engineering, School of Energy, Geoscience, Infrastructure and Society, Heriot-Watt University, Riccarton, Edinburgh, EH14 4AS, Scotland, United Kingdom. j.buckman@hw.ac.uk

Keywords: Single crystal; echinoderms; vesicle; biomineralization

Submission: 1 June 2020. Acceptance: 24 July 2020

Buckman, James O. 2020. The tube of Ditrupa bartonensis (Annelida, Serpulidae), from the Eocene of southern England: Observations on microstructure and its significance. Palaeontologia Electronica, 23(2):a37. https://doi.org/10.26879/1098 palaeo-electronica.org/content/2020/3124-ditrupa-bartonensis-tube

This is an open access article distributed under the terms of Attribution-NonCommercial-ShareAlike 4.0 International (CC BY-NC-SA 4.0), which permits users to copy and redistribute the material in any medium or format, provided it is not used for commercial purposes and the original author and source are credited, with indications if any changes are made.

creativecommons.org/licenses/by-nc-sa/4.0/ 


\section{INTRODUCTION}

Annelids within the family Serpulidae have a long history of construction of calcareous tubes (see Ippolitov et al., 2014), which are usually comprised of calcite, aragonite, or a combination of the two (Vinn et al., 2008b; Ippolitov et al., 2014; Buckman and Harries, 2020). Although often previously thought of as relatively simple structures, such tubes have more recently been shown at the microscopic level to be highly complex and variable structures (Weedon, 1994; Vinn et al., 2008b; Ippolitov et al., 2014). Investigations into the ultrastructure of serpulid tubes has illustrated at least 12 common tube fabrics (Vinn et al., 2008b; Ippolitov et al., 2014), which in conjunction with macroscopic observation on tube morphology and ornament can be used to differentiate tubes at a generic level (see Vinn et al., 2008b; Ippolitov et al., 2014; Buckman and Harries, 2020). The latter is of particular significance for fossil material, where soft part preservation is generally not found. Serpulid tube ultrastructure may undergo recrystalisation and destruction due to the processes of diagenesis, however, useful information has been recorded from at least the Middle Triassic to Jurassic (Weedon, 1994; Vinn and Furrer, 2008; Ippolitov et al., 2014), becoming more common in younger formations. As such serpulid tube ultrastructure has an important taxonomic role to play in the geological record.

Ditrupa bartonensis occurs within clay from the Eocene Barton Beds Formation of Hampshire, southern England (Figure 1), where it is found as the most abundant component of a varied calcareous worm tube assemblage, within a fauna dominated by molluscan material, and more exotic elements such as shark and ray dentition (British Museum Natural History, 1971; Morton, 2001). Despite much of the material comprising aragonite, the fauna is generally well preserved at both the macro- and micro-level. Ditrupa at the macroscopic level are simple smooth tusk-shaped tubes, which belies their intricate and unusual ultrastructure that can be elucidated through the use of scanning electron microscopy (SEM), such as reviewed and illustrated by Vinn et al. (2008c), with the study of Eocene to recent examples of the genus. In addition to Ditrupa several other serpulid genera are known to possess unique tube microstructures (Vinn 2013a,b; Kupriyanova et al. 2014) making them an important group for biomineralization studies.This paper examines the ultrastructure of examples of $D$. bartonensis and discusses the origins and nature of the observed layers.

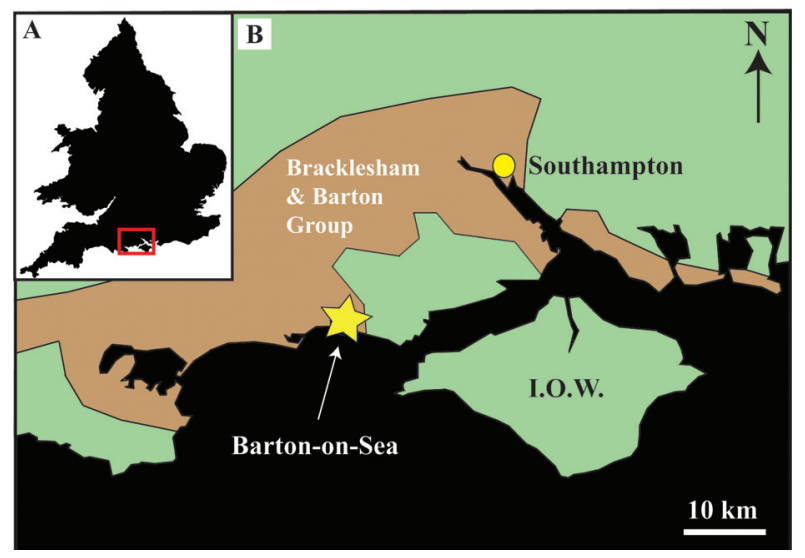

FIGURE 1. Locality map, A) England and Wales, red box outlines locality map in (B), B) locality details, illustrating the location of Barton-on-Sea, and distribution of the Eocene Bracklesham and Barton Groups (including the Barton Beds Formation). I.O.W. = Isle of Wight.

\section{MATERIALS AND METHODS}

Several dozen samples of Ditrupa bartonensis from the Eocene Barton Beds Formation, Bartonon-Sea, Hampshire, UK, were examined in polished thin section and as three-dimensional whole or broken specimens. Samples were examined uncoated in low vacuum (0.83 Torr) and gold coated in high vacuum, as secondary electron (SE) and backscattered electron (BSE) images, at between 2 and $20 \mathrm{kV}$, using an FEl Quanta 650 FEG SEM. In addition, samples were also analysed for their elemental composition using an Oxford Instruments X-MaxN $150 \mathrm{~mm}^{2}$ energy dispersive X-ray (EDX) detector. In addition, powder X-ray diffraction (XRD) on a Bruker D8 Advance Xray diffractometer with monochromatic $\mathrm{CuKa1}$ radiation was also used. All examined samples were destroyed during the process of examination.

\section{RESULTS}

\section{Taxonomy}

Family SERPULIDAE Burmeister, 1837 Genus DITRUPA Berkeley, 1835 Ditrupa bartonensis Wrigley, 1951

Figures 2-7

Description. Simple tusk-like curved tubes, expanding towards aperture, typically $1-2 \mathrm{~mm}$ in diameter, up to $15 \mathrm{~mm}$ in length. A notable swelling of the tube is commonly developed at the apertural end. Two distinct layers are clearly observed (Figure 2). The tube has a chevron-shaped growth lamellae passing through both the major layers (Figure 2). In the inner layer the chevron is vertical 

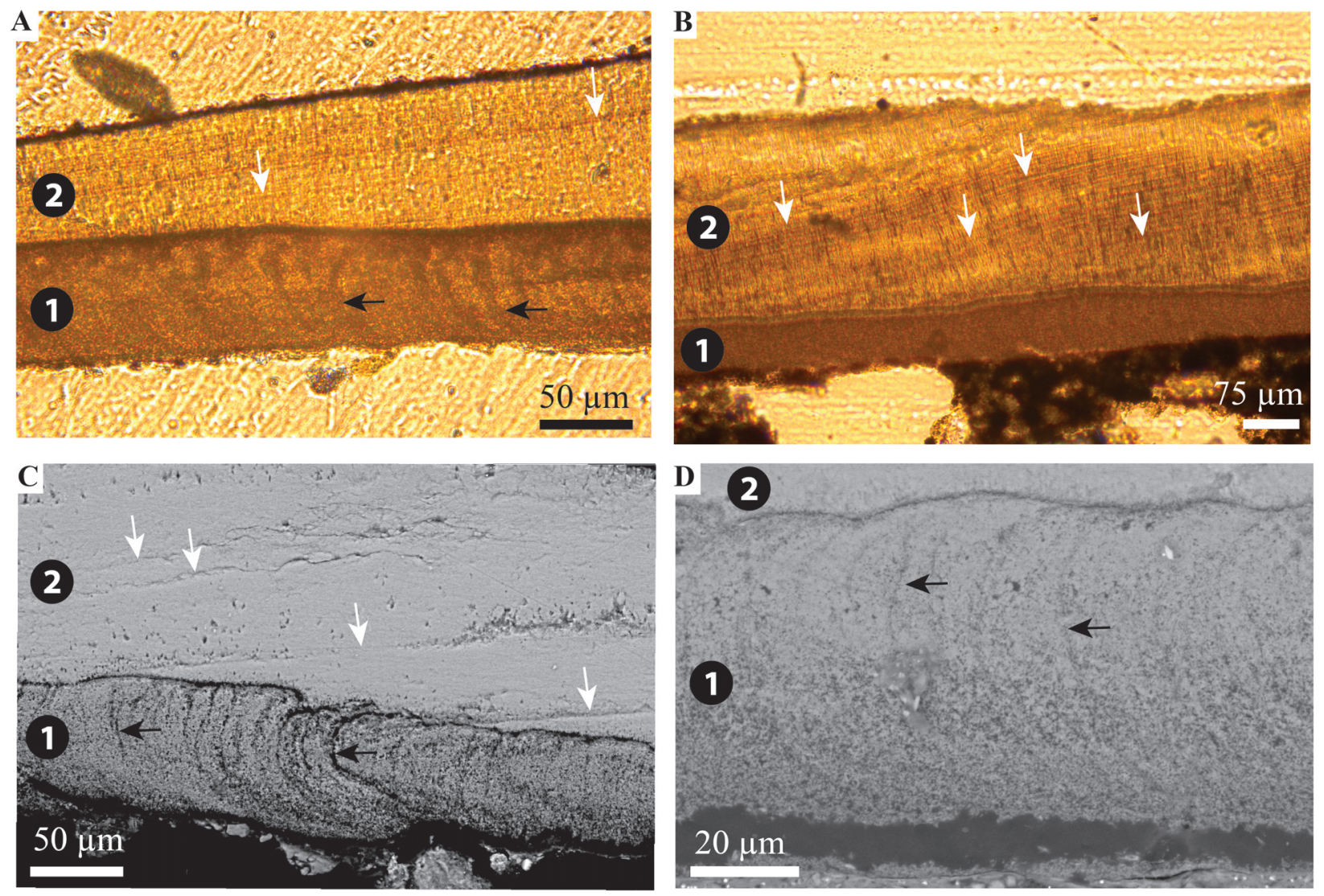

FIGURE 2. Overview, longitudinal cross-sections of Ditrupa bartonensis. A)- B) Optical images. C)-D) Scanning electron microscope, backscattered electron (BSE) images. Illustrating the two layers (1) -inner layer, and (2) -outer layer, and the overall chevron lamella character of the tube. White and black arrows indicate the position of growth lamellae within the outer (2) and inner (1) layers, respectively.

to 'C'-shaped, whereas in the outer layer it continues at an angle of approximately $10^{\circ}$ from the interface between the two layers. The outer layer comprises regularly ridged prismatic crystals (RRP) (Figures 3-5), arranged approximately perpendicular to growth lines. Crystals have a typical width of 1.54 to $5.88 \mu \mathrm{m}$, by up to $300 \mu \mathrm{m}$ in length (the thickness of the layer), with a distinct parallel ridge and groove texture on the outer surface of the crystals. Ridges and grooves in the order of 23 to $155 \mathrm{~nm}$ wide. Ridge and grooves on adjacent crystal faces (within a single crystal) are arranged in a V-shaped pattern (in which the ' $\mathrm{V}$ ' points towards the interior of the tube). Organic matter rarely observed between crystals (Figure 3B, D). Cross-sections of the crystals form a range of triangular, wedge-shaped, polygonal to more irregular shapes (Figure 4), with margins marked by peglike facets (Figure 4), that mark the position of surface ridges and grooves. Pegs range from tightly to loosely interlocking (Figure 4F). One cross-section illustrates internal structure, comprising 500-700 nm euhedral, zoned crystals (Figure 6A, B). Transverse breaks appear smooth, though closer examination shows that they often display irregular stepped conchoidal fractures, and that these surfaces have a rough undulating nature, with structure in the sub-micron range (Figure 5). Other crystals broken along their length have an apparent 'laminated' structure approximately perpendicular to the crystal long axis (Figures 3,5 ), although some breaks illustrate that these are divided into micron-sized packages that are strongly inclined to the tube surface (Figures 3B, 5D, E).

The interface between the outer and inner layers is sharply defined (Figures 2, 6C, D), with the regular ridged prismatic (RRP) crystals each initiating from a single point locus (Figure 6D). The inner layer comprises long thin acicular crystals, with polygonal, occasionally observed as hexagonal, cross-section, typically 94 to $393 \mathrm{~nm}$ by $\sim 1.5 \mu \mathrm{m}$ to $11.5 \mu \mathrm{m}$. Along the inner tube surface crystals are roughly parallel to the circumference of the lumen (Figure 7A), perpendicular to the tube long axis, 

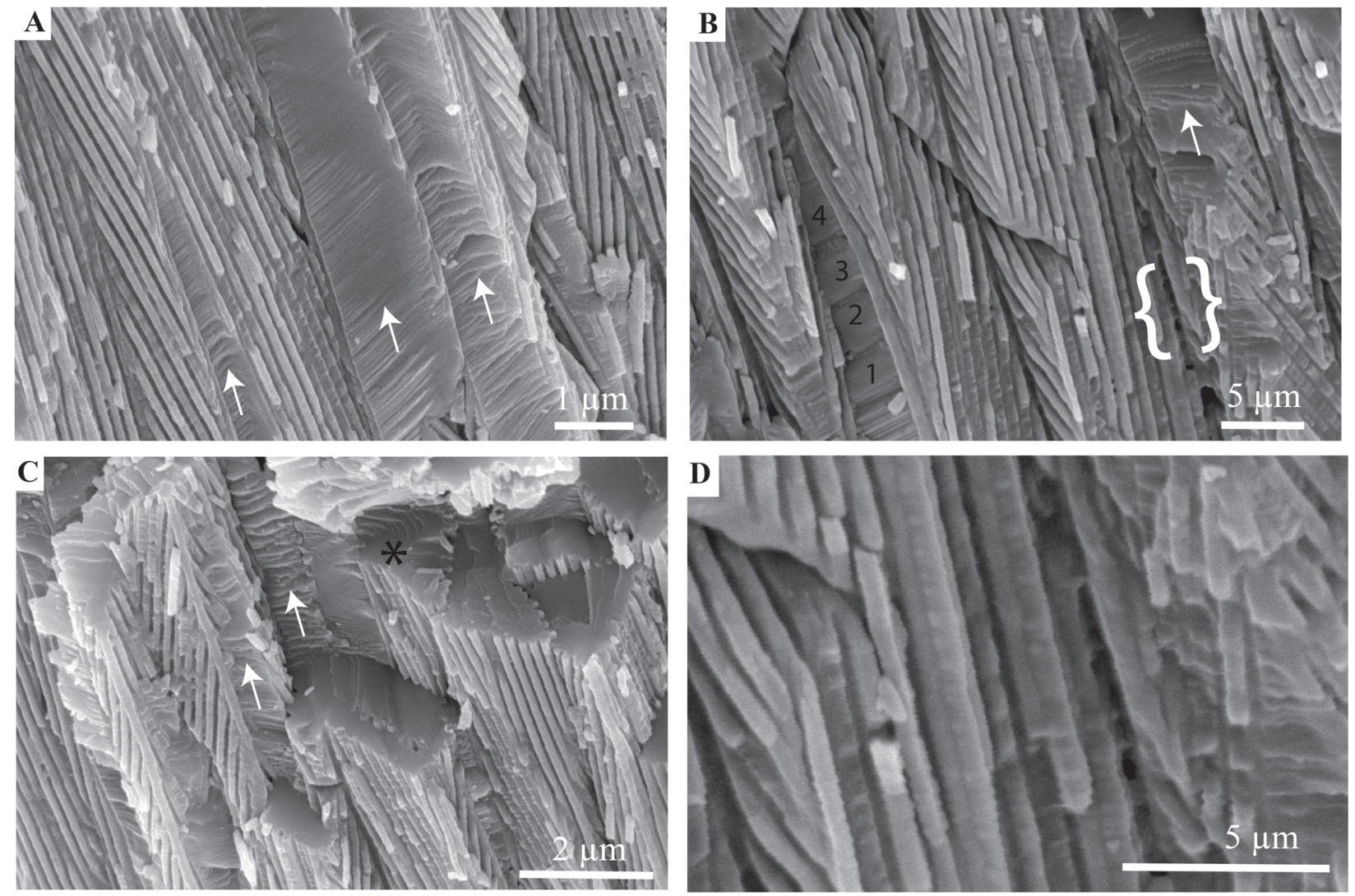

FIGURE 3. Scanning electron images of the upper structural layer from Ditrupa bartonensis. A)-D) Longitudinal views of ridged crystals. Arrows indicate locations where cleavage planes are observed (approximately perpendicular to crystal long axis) - interpreted as growth lines in Vinn et al. (2008c). Areas marked with asterisk $\left({ }^{*}\right)$ are transverse cross-sections with conchoidal fracture. In (B) area within \{\} is possible remnants of organic framework / membrane, expanded in (D). 1-4 in (B) highly inclined fracture packets (also see Figure 5).

and appear to occur in loose bundles, angled at up to $10^{\circ}$ to the line of the tube circumference (Figure 7B, C). In addition, transverse sections across tubes illustrate similar groupings and orientations (Figure 7D, E). Both the latter have a "woven" appearance (Figures 7A-D, 8). In the longitudinal section, this layer has a 'granular' appearance (Figures 7F-H, 8). The outer layer is typically four or five times as thick as the inner layer.

Composition. Powder XRD analysis indicates the occurrence of calcite, with a $\mathrm{d}_{104}$ spacing of between 3.02-3.04 (Figure 9), which equates to approximately $4-10 \mathrm{~mol}^{\circ} \mathrm{MgCO}_{3}$ (see Goldsmith and Graf 1958, table 5). EDX analysis of selected areas (approximately $50 \mu^{2}$ ) indicates that the inner layer has a higher $\mathrm{Mg}$ content (Ca:Mg ratio $\sim 15: 1$ to $19: 1)$ compared to the RRP layer (21:1 to $30: 1)$.

\section{DISCUSSION}

In general, these results agree with those found for modern and fossil Ditrupa by Vinn et al., (2008a), having an outer tube layer comprising of regularly ridged prismatic fabric (RRP). However, unlike other previously described fossil material (Eocene and Miocene), Ditrupa bartonensis also preserves the structure of the inner layer, which is identical to that described by Vinn et al. (2008c). This confirms the conservative nature of the shell structure of Ditrupa (Vinn et al., 2008c), extending its conservatism to include the whole tube microstructure from the present day to at least the Eocene. The higher $\mathrm{Mg}$ content of the inner tube layer compared to the outer layer, identified by Vinn et al. (2008c), is also present in the Barton Beds Formation Ditrupa, perhaps indicating the lack of diagenetic alteration of this material, as indicated by the generally exceptional level of preservation. The particularly excellent nature of tube preservation is also indicated by the clear appear- 

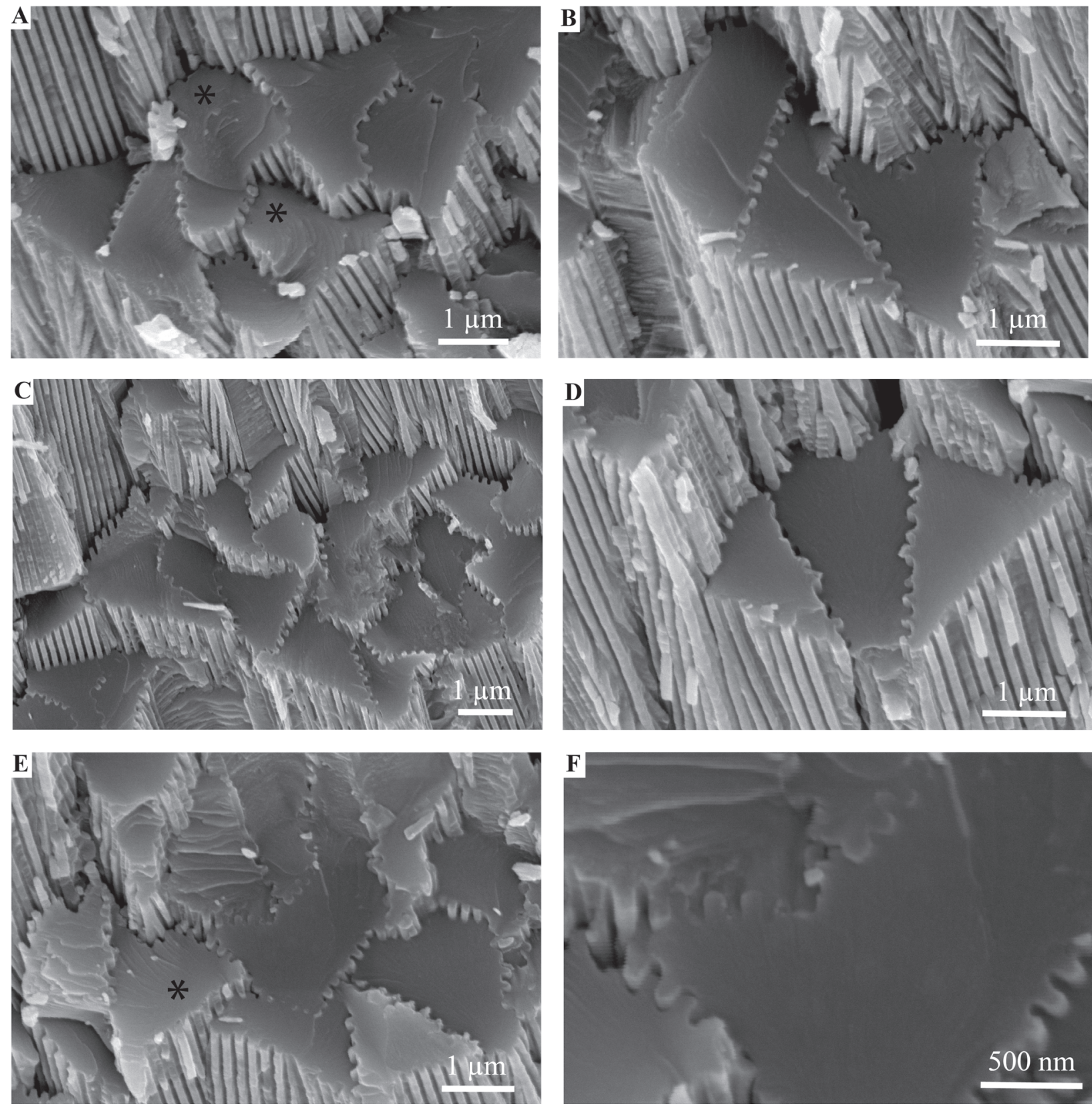

FIGURE 4. Scanning electron images of the upper structural layer from Ditrupa bartonensis. A)-F) Showing crosssections through ridged crystals. Note that crystals commonly have triangular or wedge-shaped cross-sections, although many other highly variable shapes also occur. Also ridges range from tightly to loosely interlocking. Transverse sections appear smooth (but see Figure 5), with occasional conchoidal fractures ( ${ }^{*}$ ).

ance of growth increments within both inner and outer layers, observed both optically and by scanning electron microscopy (Figure 2). Growth lines were not fully noted throughout the full tube thickness in Vinn et al. (2008c), however, those observed herein correspond exactly to those illustrated by Bandel (1986, plate 10, figure 4), with a distinctive inner ' $C$ '-shaped form, passing outwards into gently inclined lamellae. This indicates, that like many other serpulid tubes, such as Propomatoceros (Vinn et al., 2012), Pyrgopolon (Vinn et al., 2014), Serpula (Vinn and Furrer, 2008; Vinn et al., 2008a; Buckman and Harries, 2020), Spirobranchus (Weedon, 1994; Buckman, 2015 - both as Pomatoceros), and Spirorbis (Weedon, 1994) that tubes of Ditrupa are constructed around a chevronshaped lamella/growth surface. Given the nature of RRP fabric (formed from single crystals), and its 

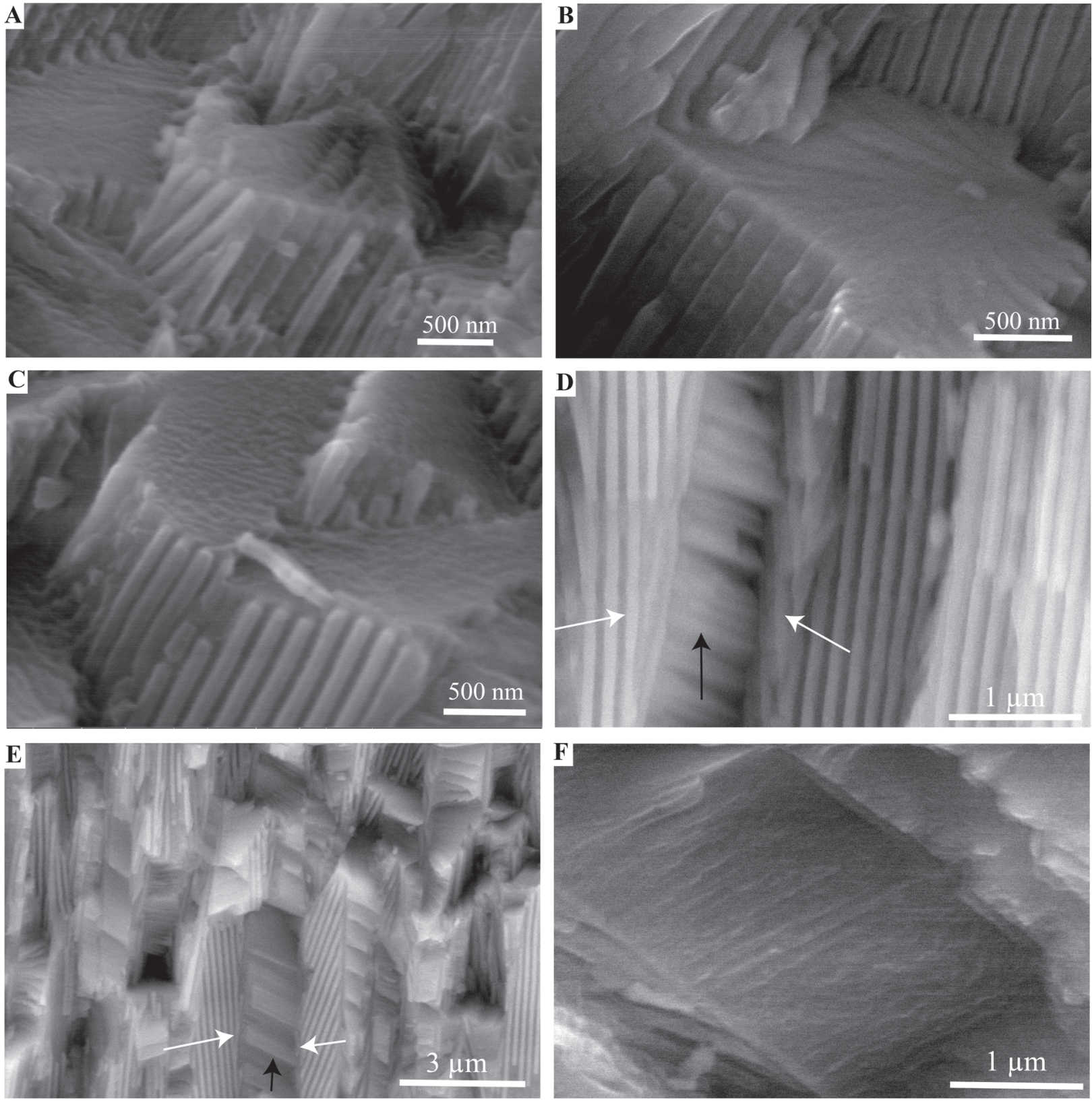

FIGURE 5. Scanning electron images of the upper structural layer from Ditrupa bartonensis. A)-C) Showing crosssections through ridged crystals, illustrating the presence of curved (conchoidal) fractures, which have a rough uneven surface. The latter possibly reflecting the occurrence of protein vesicles. (A) shallowly inclined transverse fractures, (B) fractured surface with a fan-like pattern of conchoidal fractures, passing into rod and groove ornament. D)-F) longitudinal broken sections, illustrating irregular fracture surfaces parallel to exterior ridge and groove ornament. (D) and

(E) white arrows indicate ridge and groove structure parallel to near vertical rough platey fracture (black arrow); also see Figure 3B. F) Detail of surface of near vertical rough platey fracture surface. Note images taken in low-vacuum mode, on uncoated surfaces. 

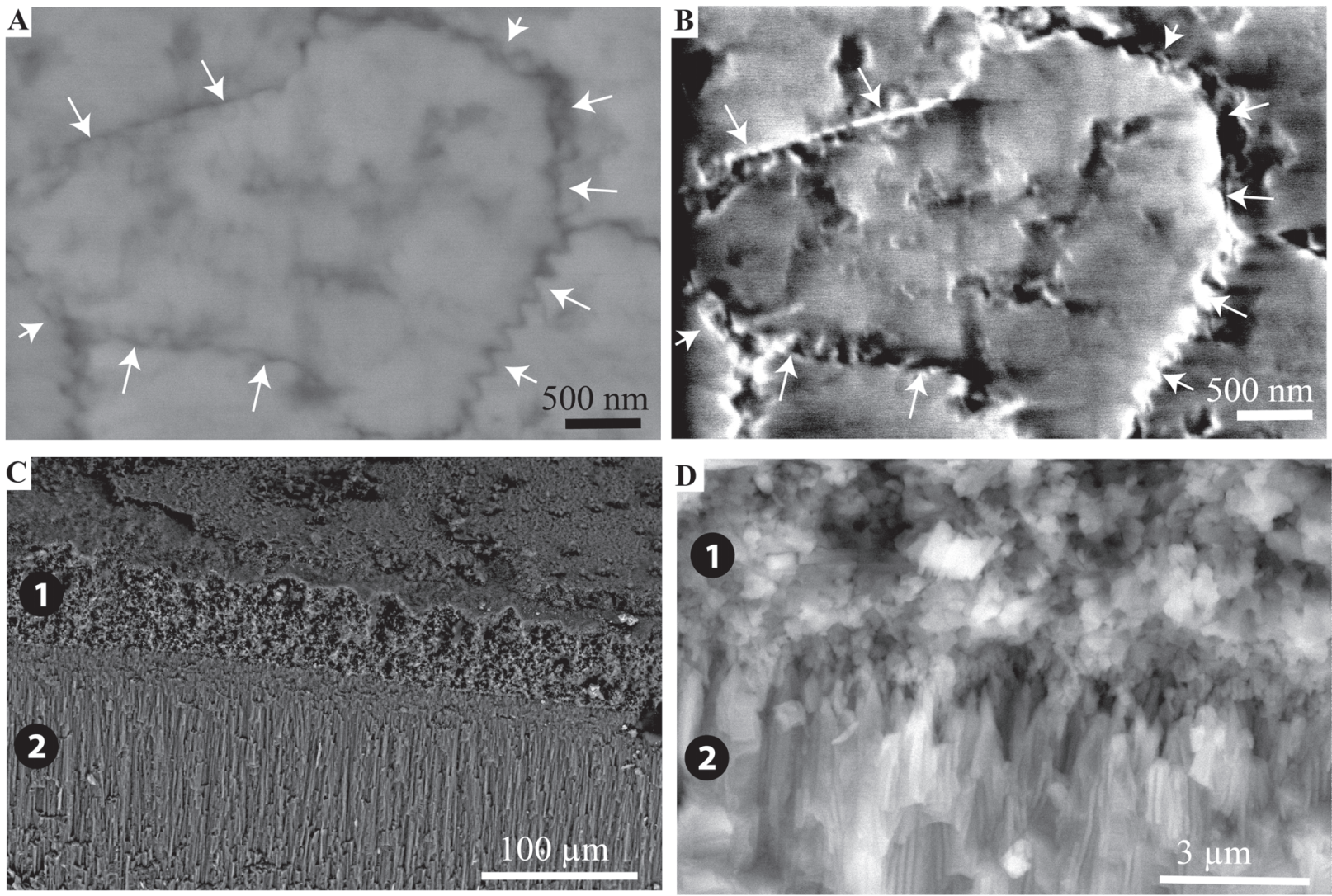

FIGURE 6. Scanning electron images of Ditrupa bartonensis. A), B) Transverse polished section through a single ridged crystal in the outer layer of $D$. bartonensis. A) Backscattered electron (BSE) image, B) gaseous secondary electron (GSE) image, of the same area as in (A). Illustrating what appears to be an indication of internal crystal structure. Arrows indicate the edge of the crystal. C), D) Longitudinal sections showing layer 1 (inner layer) and 2 (outer layer). Note in $(D)$ at the interface between the layers that the regular ridged prismatic crystals each initiate from an individual point locus.

large areal extent, it is unlikely that the annelid inhabiting the tube constructed the outer tube in the fashion of other serpulids such as Spirobranchus (see Neff, 1971- as Pomatoceros) but outer tube mineralization was likely controlled by organic mediation (see Vinn et al., 2008b).

\section{Significance of New Observations on RRP Structure}

Observations on the regularly ridged prismatic fabric crystals have previously shown that these are unusual structures, with no other known occurrences amongst the annelids (Vinn et al., 2008b, c). The observation of stepped conchoidal fractures within regularly ridged prismatic crystals is of significance. Such fracture surfaces are not normal for calcite cleavage and have been identified within the calcitic spines of echinoderms, which have been formed from single crystals (Towe, 1967; Addadi and Weiner, 1992). Therefore, their occurrence within RRP appears to confirm the single crystal origin. Calcite echinoderm spines, produced from single calcite crystals are of great interest, as they can have a range of external ornamentation, including radially ridged ornament (see Addadi and Weiner, 1992, figure C, upper left) of a similar nature to the ridges from RRP structure. Such ornamentation (within echinoderms) display rounded-off forms and geometries (Addadi and Weiner, 1992), which are atypical of biotic and abiotic calcite, but are present within the ridges and grooves of RRP structure. According to Addadi and Weiner (1992), echinoderm plates contain acidic proteins within their crystal structure (protein occlusions $\sim 80 \mathrm{~nm}$ in diameter (Su et al., 2000)), with proteins arranged parallel to the c-axis on the $\{110\}$ plane, with the effect that natural calcite cleavage (parallel to (104) faces) terminates within protein, causing conchoidal fractures and strengthening the calcite crystals. Vinn et al. (2008c) interpret the ridging of RRP structure as an adaption for tube strengthening, which may be further supported by 

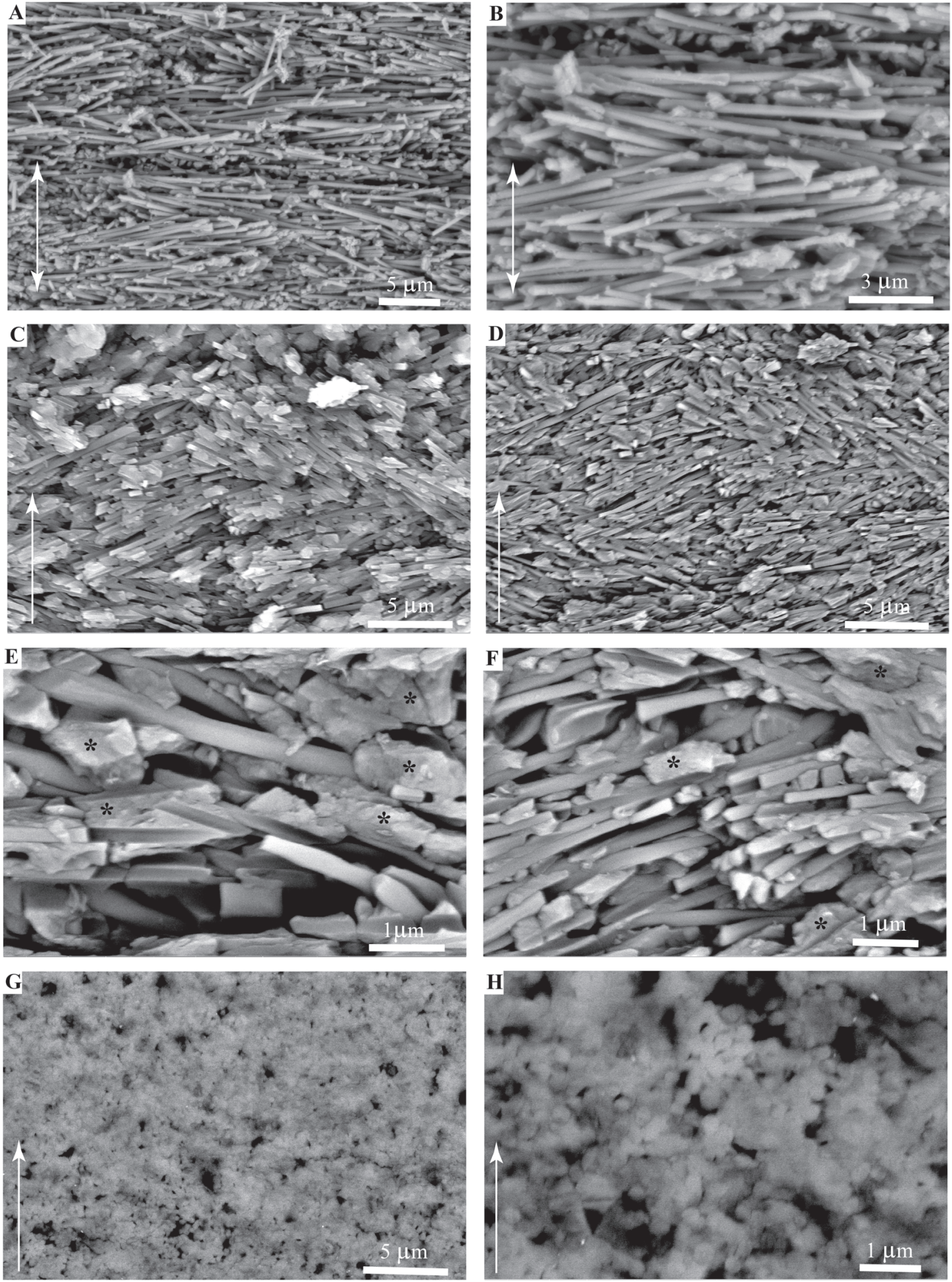

FIGURE 7. Details of the microfabric of the inner layer of Ditrupa bartonensis. A)-C) Views of the inner tube surface (arrows indicate tube long axis), with loosely arranged bundles of long slender crystals, oriented perpendicular to tube long axis (with an approximate deviation of $10^{\circ}$ within the plane of lamellae). D), E) Transverse vertical section (arrow indicates direction to upper surface) with loosely arranged bundles of long slender crystals, oriented parallel to tube circumference (with a maximum deviation of $\sim 15^{\circ}$ within the plane of lamellae). In (E) prismatic crystals occur associated with granular calcite $\left({ }^{*}\right)$, of possible authigenic origin. F)-H) Longitudinal vertical section (arrow indicates direction to upper surface), with apparent granular fabric. 


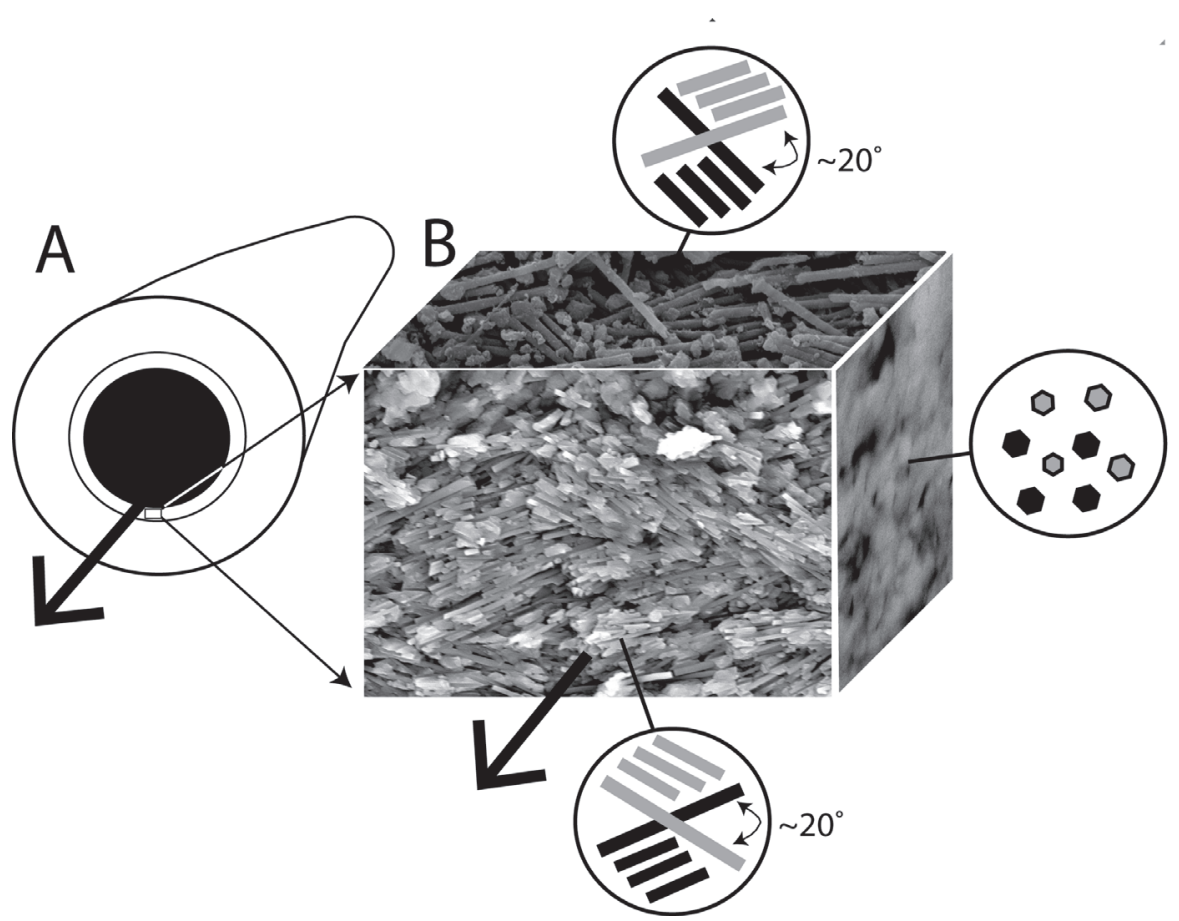

FIGURE 8. 3D reconstruction of the inner layer of Ditrupa bartonensis, illustrating fabric appearance in relationship to tube long axis (large black arrows). A) Cartoon of tube, B) virtual 3D reconstruction using micrographs.

comparison to the mineralization and functionality of echinoderm spines (see Smith, 1990; Su et al., 2000). Structure herein interpreted as part of an irregular conchoidal fracture system (Figures 3A, C, 5E, F), but previously as growth lamellae (Vinn et al., 2008c), illustrates that alteration of normal calcite cleavage fractures (due to the incorporation of protein vesicles), in this case in the event of applied stress results in complex 3D conchoidal fractures that tie in with the unusual surface ridge and groove ornament (Figure 5E, F); which appears to reduce transverse breakage of the RRP structure, thus increasing structural integrity.

Echinoderm spines and other echinoderm plates are formed within vesicles inside cells (Addadi and Weiner, 1992). Crystalisation is initiated as an amorphous calcium carbonate (ACC) precursor, which can be pre-formed into intricate shapes before transformation into single crystals (Politi, 2004). Such an origin within vesicles inside cells, for RRP structure is unlikely, as this would require a complex mechanism to emplace crystals after expulsion from the annelid, to form the tightly interlocking pattern of crystals in the external layer. Single (and multiple) crystal secretion within vesicles can occur out with cells (Addadi and Weiner, 1992), although this also seems too complex to explain the observed patterns of crystals formed.
Although formation of single calcite crystals is only currently known from echinoderms (Towe, 1967; Addadi and Weiner, 1992; Politi et al., 2004), Politi et al. (2004) speculated that the method of forming single calcite crystals from ACC precursors may be more common in other organisms. Therefore, in conjunction with some form of organic membrane or organic matter mediated growth this might explain the growth and form of RRP structure. In Ditrupa, ACC may possibly be seeded within an organic matrix (on the outer surface of the inner layer), with shape moulded by a surrounding organic envelope/scaffold (macromolecular matrices of Vinn et al., 2008c), before transformation into single crystals. However, Vinn et al. (2008c) did not note the occurrence of organic membranes between individual RRP crystals, and only one example of organic matter between individual crystals has been tentatively noted from the current material (Figure 3C, E). Alternatively, given that 'growth' lamellae are clearly observed in the RRP layer (Figure 2A, B), as also noted by Vinn et al. (2008c), and that echinoderms are known to be able to repair broken crystals through the addition of new ACC to form optically continuous crystals (Politi, 2004), RRP structures may be incrementally refreshed by the annelid. The latter could include the addition of ACC and potentially some form of 


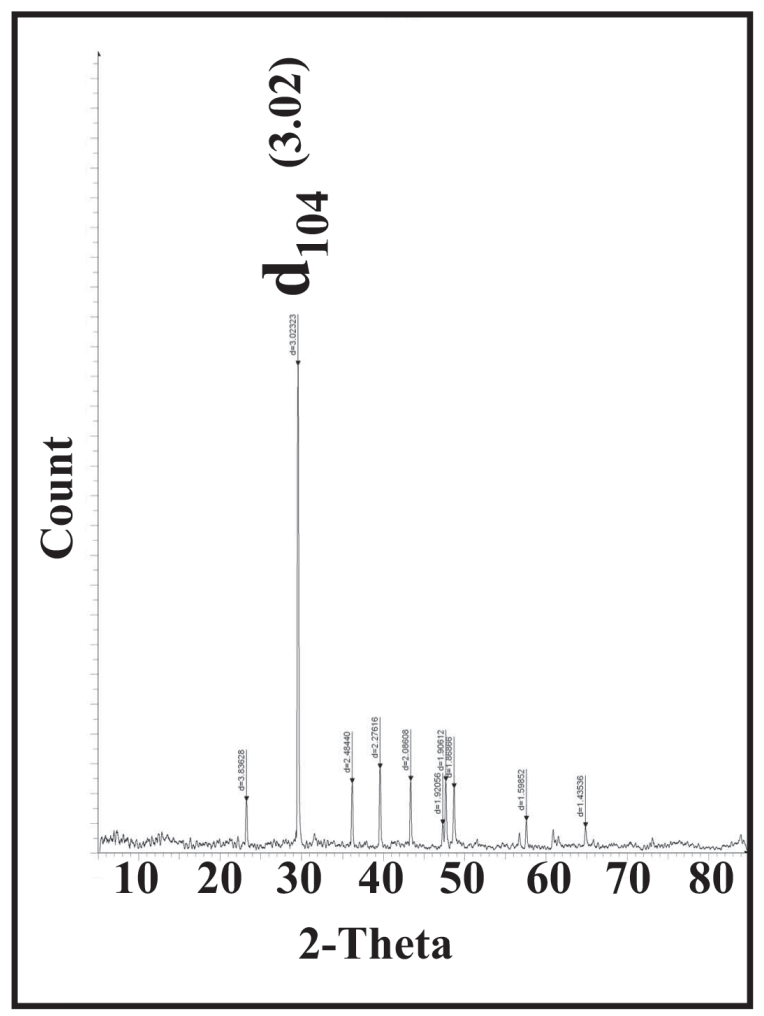

FIGURE 9. XRD trace of whole powdered tube of Ditrupa bartonensis. Illustrating the occurrence of calcite, with no other carbonate phases.

organic self-forming template. The apparent internal structure of one discrete RRP element (Figure $6 \mathrm{~A}, \mathrm{~B})$ is of interest. These appear to indicate an internal microstructure comprised of granular or possibly rod-like elements (no vertical sections observed showing internal structure). In the first instance, this might tend to suggest that the individual elements in RRP structure are not single crystals. However, single crystal echinoderm spines can have complex internal geometries to their stereom (Figure 10). In which case, the observed RRP sub-structure could represent such added complexity, yet still be formed from single crystals. Nevertheless, comparative investigations between echinoderm calcite mineralization and RRP are strongly recommended, though beyond the scope of the current work.

\section{Inner Layer Structure and Nomenclature}

The structure of the inner layer of Ditrupa bartonensis is identical to that illustrated from modern materials by Vinn et al. (2008c), which was classified as an irregularly orientated prismatic (IOP) structure. However, IOP structure as defined by Vinn et al. (2008b) does not correspond well with the fabric described by Vinn et al. (2008c) or seen herein:

i) IOP structure comprises crystals composed of finer rod-like components, arranged parallel to the crystal long axis, with no sharp boundary between individual sub-structural elements;

ii) IOP structure comprises of irregularly (randomly) orientated prismatic elements.

Neither is true for the internal layer of Ditrupa, which is formed from single long slim crystals, with sharp margins, and good separation observed between individual elements. In addition, the individual elements display a strong preferred orientation perpendicular to the tube long axis, and with a limited deviation of around $10^{\circ}$ from this, in both the vertical plane, and within the plane of the tube circumference (Figures 7, 8). Consideration of other described annelid fabrics (see Vinn et al., 2008b) indicates that this fabric does not fit any currently described fabrics (see Vinn et al., 2008b). We strongly recommend the setting up of a new fabric type, which is here termed simple preferentially orientated prismatic (SPOP), erected around the fabric graphically illustrated in Figure 8.

\section{CONCLUSIONS}

Regularly ridged prismatic (RRP) material that forms the outer layer of the tube of Ditrupa, may have much in common with the calcitic spines and plates of echinoderms, both forming from single crystals after an amorphous calcium carbonate (ACC) precursor, and containing a proportion of organic material. As with echinoderms, Ditrupa would have benefited from increased structural rigidity (strength), and the mitigation of breakage through cleavage planes. Both echinoderm and Ditrupa single crystals exhibiting a conchoidal fracture due to the incorporation of acidic proteins within their structure. The exact mechanisms employed for the formation of such crystals within Ditrupa are far from clearly understood and merit future research.

The internal tube layer of Ditrupa bartonensis compares favourably with that illustrated from extant species, comprising long thin prismatic crystals, with a strong preference for alignment parallel to the circumference of the tube, and perpendicular to the long axis. This indicates that both external and internal tube fabrics are conservative in nature, with a history of occurrence from at least the Eocene to present. Detailed observation of the tube fabric indicates that it does not comply with the definition for irregularly orientated prismatic 

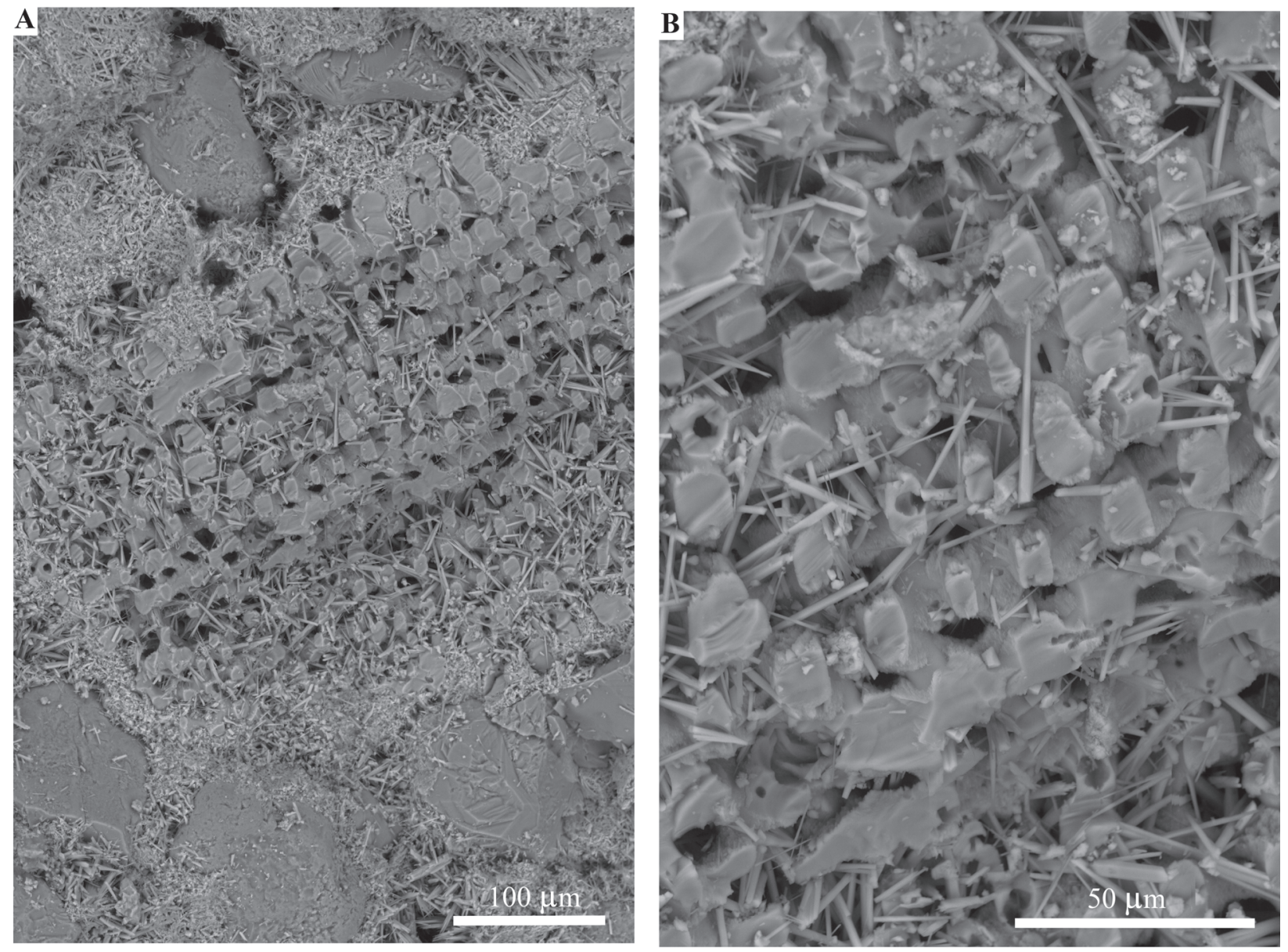

FIGURE 10. Echinoderm spine constructed from single calcite crystal. Possible analogue for formation of RRP structure. A) Overview, B) Close-up.

(IOP) structure, having a different microstructure and with a more constrained range of prismatic crystal orientations. Therefore, the term simple preferentially orientated prismatic (SPOP) structure is used herein for the internal layer of the tubes of Ditrupa.

\section{ACKNOWLEDGEMENTS}

Thanks to the Institute of GeoEnergy Engineering, Heriot-Watt University (HWU) for use of
SEM-EDX facilities, the Lyell Centre (HWU) for access to digital optical microscopy, and the School for Engineering and Physical Sciences (HWU) for XRD analysis. Also, special thanks to Alan Morton for the donation of a variety of Eocene serpulid materials, some of which were utilised during the present research. This work has not been funded by any grants, representing the author's personal research over a number of years.

\section{REFERENCES}

Addadi L. and Weiner, S. 1992. Control and design principles in biological mineralization. Angewandle Chemie International, 31:153-169. https://doi.org/10.1002/anie.199201531

Bandel, K. 1986. The reconstruction of "Hyolithes kingi" as annelid worm from the Cambrian of Jordan. Mitteilungen aus dem Geologisch-Paläontologisschen Institut der Universität Hamburg, 61:35-101. 
Berkeley, M.J. 1835. Observations upon the Dentalium subulatum of Deshayes. Zoological Journal, London, 5:424-427.

British Museum Natural History. 1971. British Caenozoic Fossils, fourth ed. British Museum (Natural History), London.

Buckman, J. 2015. An overview of the tube fabric of Pomatoceros (Polychaeta, Serpulidae), illustrated by examples from the British Isles. Zoologischer Anzeiger, 259:54-56. https:// doi.org/10.1016/j.jcz.2014.11.005

Buckman, J.O. and Harries, D.B. 2020. Reef forming Serpula vermicularis from Scotland and Ireland: tube structure, composition and implications. Zoologischer Anzeiger, 288:53-65. https://doi.org/10.1016/j.jcz.2020.07.003

Burmeister, H. 1837. Handbuch der Naturgeschichte. Part 2, Enslin, Berlin.

Goldsmith, J.R. and Graf, D.L. 1958. Relation between lattice constants and composition of the Ca-Mg carbonates. The American Mineralogist, 43:84-101.

Ippolitov, A.P., Vinn, O., Kupriyanova, E.K., and Jäger, M. 2014. Written in stone: history of serpulid polychaetes through time. Memoirs of Museum Victoria, 71:123-159.

Kupriyanova, E.K., Vinn, O., Taylor, P.D., Schopf, J.W., Kudryavtsev, A., and Bailey-Brock, J. 2014. Serpulids living deep: calcareous tubeworms beyond the abyss. Deep-Sea Research Part I, 90:91-104.

Morton, A. 2001. http://www.dmap.co.uk/fossils/ (last viewed May 2020).

Neff, J.M. 1971. Ultrastructural studies of the secretion of calcium carbonate by the serpulid polychaete worm Pomatoceros caeruleus. Zeitschrift für Zellforschung und mikroskopische Anatomie, 120:160-168.

Politi, Y., Arad, T., Klein, E., Weiner, S., and Addadi, L. 2004. Sea urchin spine calcite forms via a transient amorphous calcium carbonate phase. Science, 306:1161-1164. https://doi.org/ 10.1126/science. 1102289

Smith, A.B. 1990. Biomineralization in echinoderms, p. 117-147. In Carter, J.G. (ed.), Skeletal Biomineralization: Patterns, Processes and Evolutionary Trends Volume 1. Van Nostrand Reinhold, New York. https://doi.org/10.1029/SC005

Su, X., Kamat, S., and Heuer, A.H. 2000. The structure of sea urchin spines, large biogenic single crystals of calcite. Journal Material Science, 35:5545-5551. https://doi.org/10.1023/ A:1004840609666

Towe, K.M. 1967. Echinoderm calcite: single crystal or polycrystalline aggregate. Science, 157:1048-1050. https://doi.org/10.1126/science.157.3792.1048

Vinn, O. 2013a. On the unique isotropic aragonitic tube microstructure of some serpulids (Polychaeta, Annelida). Journal of Morphology, 274:478-482.

Vinn, O. 2013b. SEM study of semi-oriented tube microstructures of Serpulidae (Polychaeta, Annelida): implications for the evolution of complex oriented microstructures. Microscopy Research and Technique, 76:453-456.

Vinn, O. and Furrer, H. 2008. Tube structure and ultrastructure of serpulids from the Jurassic of France and Switzerland, its evolutionary implications. Neues Jahrbuch für Geologie und Paläontologie, Abhandlungen, 250:129-135.

Vinn, O., Jäger, M., and Kirsimäe, K. 2008a. Microscopic evidence of serpulid affinities of the problematic fossil tube "Serpula" etalensis from the Lower Jurassic of Germany. Lethaia, 41:417-421.

Vinn, O., Ten Hove, H.A., Mutvei, H., and Kirsimäe, K. 2008b. Ultrastructure and mineral composition of serpulid tubes (Polychaeta, Annelida). Zoological Journal Linnean Society, 154:633-650. https://doi.org/10.1111/j.1096-3642.2008.00421.x

Vinn, O., Mutvei, H., Ten Hove, H.A., and Kirsimäe, K. 2008c. Unique Mg-calcite skeletal ultrastructure in the tube of the serpulid polychaete Ditrupa. Neues Jahrbuch für Geologie und Paläontologie - Abhandlungen, 248:79-89. https://doi.org/10.1127/0077-7749/2008/ 0248-0079

Vinn, O., Kupriyanova, E.K., and Kiel, S. 2012. Systematics of serpulid tubeworms (Annelida, Polychaeta) from Cretaceous and Cenozoic hydrocarbon-seep deposits in North America and Europe. Neues Jahrbuch für Geologie und Paläontologie, Abhandlungen, 256:315-325.

Vinn O., Hryniewicz K., Little C.T.S., and Nakrem H.A. 2014. A Boreal serpulid fauna from Volgian-Ryazanian (latest Jurassic-earliest Cretaceous) shelf sediments and hydrocarbon seeps from Svalbard. Geodiversitas, 36:527-540.

Weedon, M.J. 1994. Tube microstructure of recent and Jurassic serpulid polychaetes and the question of the Palaeozoic 'spirorbids'. Acta Palaeontologica Polonica, 39:1-15. 
Wrigley, A. 1951. Some Eocene serpulids. Proceedings of Geologists Association, 62:177-202. https://doi.org/10.1016/S0016-7878(51)80020-8 